and solid foods. This latter problem is infinitely more complex since it involves the study of a much larger number of textural properties.

The figures in this paper are taken from Industrial Rheology by Philip Sherman, published by Academic Press, and are reproduced with their permission.

\title{
REFERENCES
}

Angel, S. \& Kramer, A. (1969). F. Texture Studies 1, 90.

Bendall, J. R. (1951). F. Physiol., Lond. Ir4, 7 I.

Bendall, J. R. \& Davey, C. L. (1957). Biochim. biophys. Acta 26, 93.

Bourne, M. C. (1965). Fd Technol., Champaign 19, 413.

Bourne, M. C. (I968). F. Fd Sci. 33, 223.

Bourne, M. C., Moyer, J. C. \& Hand, D. B. (1966). Fd Technol., Champaign 20, 522.

Brennan, J. G., Jowitt, R. \& Mughsi, O. A. (1970). 7. Texture Studies r, I67.

Cornford, S. J., Axford, D. W. E. \& Elton, G. A. H. (I964). Cereal Chem. 4r, 2 r6.

Friedman, H. H., Whitney, J. E. \& Szczesniak, A. S. (1963). F. Fd Sci. 28, 390.

Glucklich, J. \& Shelef, L. (I $962 a)$. Cereal Chem. 39, 242.

Glucklich, J. \& Shelef, L. (1962b). Kolloidzeitschrift r81, 29.

Howard, P. L. \& Heinz, D. E. (r970). F. Texture Studies 1, 185 .

Inokuchi, K. (1955). Bull. chem. Soc. Japan 28, 453.

Kishimoto, A. \& Maekawa, E. (1962). Bull. fap. Soc. scient. Fish., 28, 803.

Kramer, A. \& Backinger, G. (1959). Food 28, 85.

Kramer, A., Burckhardt, G. J. \& Rogers, H. P. (1951). Canner 112, 34.

Kramer, A. \& Hawbecker, J. V. (1966). Fd Technol, Champaign 20, 209.

Kulwich, R., Decker, R. W. \& Alsmeyer, R. H. (1963). Fd Technol, Champaign r7, 201.

Mohsenin, N. N., Cooper, II. H. \& Tukey, L. D. (1963). Trans Am. Soc. agric. Engrs 6, 85.

Mohsenin, N. N. \& Göhlich, H. (I962). F. agric. Fngng Res. 7, 300.

Prentice, J. H. (1968). Monogr. Soc. chem. Ind. no. 27, p. 265.

Prentice, J. H. \& Chapman, H. R. (I969). F. Dairy Res. 36, 269.

Shama, F. \& Sherman, P. (1966). F. Fd Sci. 31, 699.

Shama, F. \& Sherman, P. (1968). Monogr. Soc. chem. Ind. no. 27, p. 77.

Shama, F. \& Sherman, P. (1970). J. Texture Studies I, 196.

Shaw, D. J. (1963). In Rheology of Emulsions p. 125 [P. Sherman, editor]. London: Pergamon Press.

Shelef, L. \& Bousso, D. (1964). Rheol. Acta 3, 168.

Sherman, P. (I970). Industrial Rheology: with particular reference to foods, pharmaceaticals and cosmetics. London: Academic Press.

Shimizu, 'T., Fukawa, H. \& Ichiba, A. (1958). Cereal Chem. 35, 34.

Somers, F. (1965). F. Fd Sci. 30, 922.

Sone, T. (1961). F. phys. Soc. Fapan 16, 961.

Sone, 'T., Fukushima, M. \& Fukada, E. (1962). Proc. int. Dairy Congr. xvi. Copenhagen Vol. B, p. 165.

Szczesniak, A. S. (1963). F. Fid Sci. 28,385 .

Szczesniak, A. S., Brandt, M. A. \& Friedman, H. H. (1963). F. Fd Sci. 28, 397.

Szczesniak, A. S. \& Smith, B. J. (1969). J. Texture Studies 1, 65.

Ward, A. G. \& Cobbett, W. G. (r g68). Monogr. Soc. chem. Ind. no. 27, p. ror.

Whitehead, J. \& Sherman, P. (1967). Fd Technol., Champaign 21, 152x.

Wood, F. W. (1968). Monogy. Soc. chem. Ind. no. 27, p. 40.

\section{Some aspects of the measurement of flavour}

\author{
By D. G. LAND, Food Research Institute, Norwich
}

The nutritional importance of those constituents of food which contribute to flavour is not due to their fulfilling a bodily requirement, but to their influence on acceptance and, therefore, consumption of food. Consequently, flavour is a factor 
which affects the practical nutritional value of most foods and its measurement is relevant to nutrition.

Flavour is the sensation which is perceived by an animal as an integrated response to the stimulation of the nose and buccal cavity by the chemical constituents of food. It can only have meaning in the context of a perceiving organism, and is expressed by the behaviour of that organism. In most flavour measurements the organism is man, in the form of members of a 'taste panel'. Although it is possible to relate chemical and physical measures to flavour, the primary measurement must be biological, and measurement of flavour is measurement of biological response and should be treated as such.

Sensory testing, of which flavour measurement is a part, has, in the past, suffered from a reputation for being 'subjective'-used as a derogatory term meaning very variable and not subject to generally accepted criteria for scientific measurement. Although in some cases this view has been justifiable, sensory testing can be made relatively precise and reproducible provided it is carried out with knowledge and understanding of the biological detector which is being used. As the subject is wide, with many different procedures which may be applied to different specific problems (Amerine, Pangborn \& Roessler, I965; ASTM, r968) only selected aspects are illustrated here. These are: flavour differences due to treatments, and the contribution of particular constituents to the flavour of a whole commodity.

One of the most frequent uses of sensory testing is to detect whether a particular treatment has resulted in any difference in flavour. There are several methods available (Amerine et al. 1965; ASTM, 1968). However, it is often not so much of interest to know whether or not there is a detectable difference, but how large is the difference? What is the effect of this difference on acceptance, and what are the characteristics of the perceived difference?

Information on all three questions may be obtained by means of a technique which was developed originally by Kramer \& Ditman (1956) and, after 3 years' investigation of methods for measurement of flavour effects caused by pesticide treatments, was adopted in a slightly modified form by the National Canners Association and the Food Committee of the American Society for Quality Control (Mahoney, Stier \& Crosby, $1957 a, b$ ).

The technique consists of a series of paired comparison tests in which the degree of difference between each member of a set of test samples and a labelled reference sample is rated on a five-point difference scale (none, very slight, slight, moderate, large). The set contains at least one hidden control sample. The test also requires the judge to give a separate indication of whether the sample is better, the same or worse than the reference, or as appropriate, acceptable or not acceptable, followed by comments on the nature of the difference.

The degree of difference from triplicate tests is analysed by means of a simplified form of analysis of variance based on ranges (Mahoney et al. 1957b; Tukey, 1953). Judge-performance is first analysed, and only the results of those judges fulfilling specified criteria are used for the treatment analysis. This technique, known as the Multiple Comparison Method, is illustrated by means of results from current 
investigation on the influence of place of growth (centre) on the flavour of carrots (Land \& Griffiths, unpublished observations). All samples of Autumn King Red-core carrots grown at the various centres differ significantly in flavour from the control (Fig. I). The internal variability is reflected by the difference between the control and reference samples, and the magnitude of the $5 \%$ and $\mathrm{I} \%$ probability levels. The differences found for the control samples are very similar in size to those

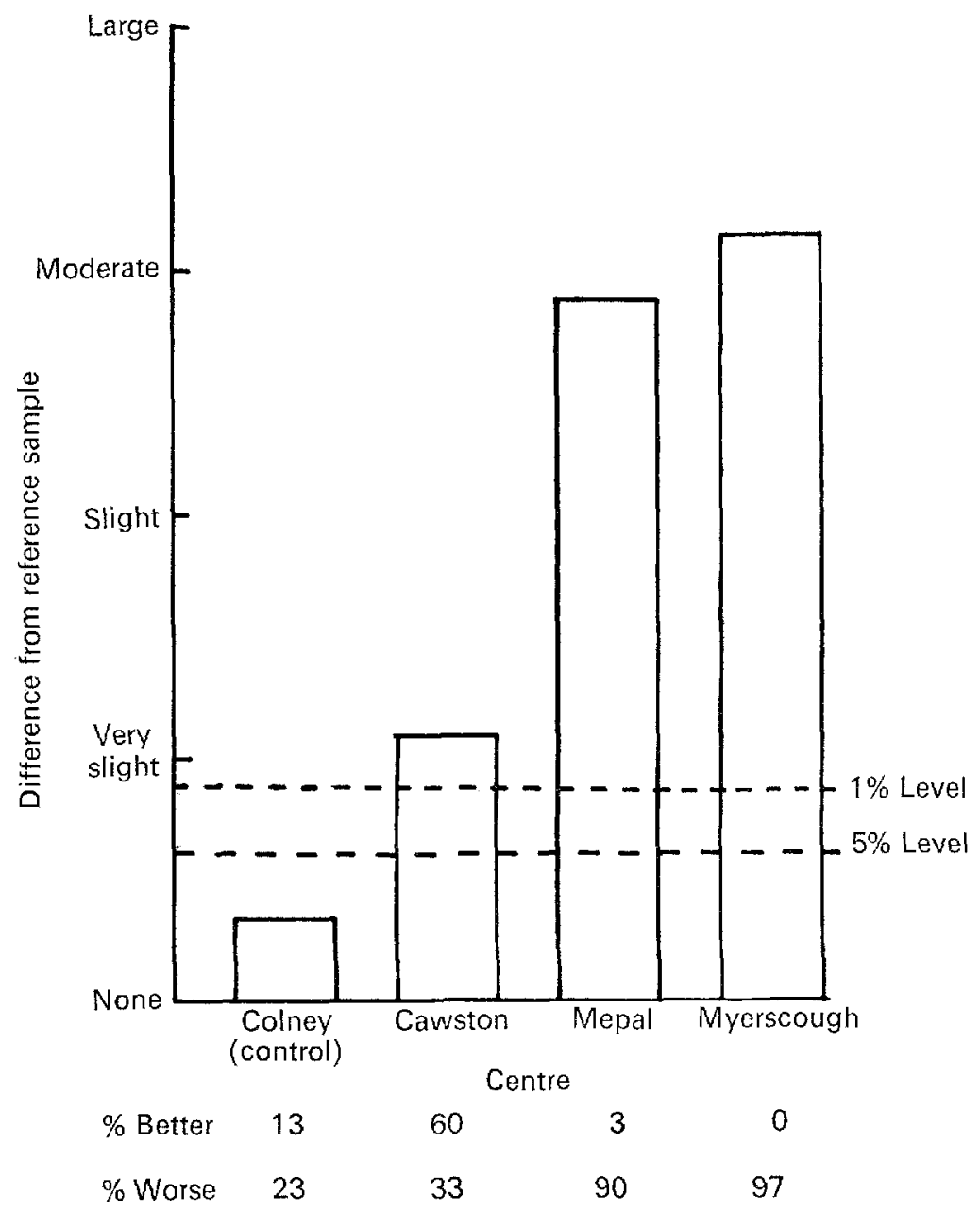

Fig. I. Use of the multiple comparison method to measure the extent of differences in carrot flavour between Autumn King Red-core carrots grown at different centres.

found using the rather similar Two-Sample Difference Test (Hall, Tarver \& McDonald, 1959) and rather less than those found in the original work (Mahoney et al. $1957 a, b$ ). The preference-results clearly indicate the adverse direction of the difference at Mepal and Myerscough, while the results for Cawston are less clear-cut, as would be expected with a smaller difference. Preference data such as this are limited strictly to the test population and a quite different method is required to 
establish preferences which are applicable to the general public. However, the laboratory panel may be used as a pointer. Comments on the character of the difference are much less precise and cannot be analysed statistically. The results (Table I), however, do indicate clear differences which are in accord with the

Table I. Characterization of flavour differences between carrots (Autumn King Red-core) grown at different centres

\begin{tabular}{lcccc}
\multicolumn{1}{c}{ Quality } & $\begin{array}{c}\text { Coiney } \\
\text { (hidden control) }\end{array}$ & Cawston & Centre & \\
No difference & 17 & 0 & 2 & Myerscough \\
Sweeter & 4 & 26 & 0 & 0 \\
Less sweet & 0 & 0 & 7 & I \\
Unpleasant, low carrot & 3 & 2 & 16 & 20 \\
Bitter & 1 & 0 & 2 & 3 \\
Stale, musty & $\mathrm{I}$ & 0 & 2 & 3 \\
Others & 4 & $\mathrm{I}$ & 4 & 3 \\
Total comments & 30 & 29 & 33 & 35 \\
Total judgements & 30 & 30 & 30 & 30
\end{tabular}

preference data. Some indication of the 'noise' in these data is given by the results for the control, which are mostly 'no difference' with eleven other comments, most of which were qualified by 'slightly'. The 'tail' on these data is usually fairly consistent with the major qualities. For example, the 'other qualities' at Myerscough were: 'more watery', 'foreign' and 'more salty' which are unlikely to be regarded as desirable qualities.

The above method of characterization is one of free description by experienced but not expert judges. The best-known method for characterization of qualities is the Flavour Profile Method which was developed at the Arthur D. Little Research Laboratories (Sjöström, Cairncross \& Caul, 1957) and critically reviewed by Amerine et al. (1965). This method uses four to six very highly trained and experienced judges using a form of free description in which amplitude and time-sequence of qualities perceived are recorded. A consensus result is then agreed by open discussion among the judges.

Another approach to the characterization of qualities present was developed by Tilgner $(1962,1965)$ using a dilution technique in which the dominant qualities are characterized by free description at stages of increasing dilution of the food. This results in threshold dilution values for the different qualities present.

A rather different method using experienced but not necessarily highly trained judges has arisen from an extensive study of odour description and classification (Harper, Bate-Smith \& Land, I968; Harper, Bate-Smith, Land \& Griffiths, I968; Harper, Land, Griffiths \& Bate-Smith, I 968). The technique involves a preliminary phase in which relevant qualities are determined by characterization using comprehensive lists of odour qualities (Harper, Bate-Smith, Land \& Griffiths, I968) followed by open discussion and clarification of these and any additional terms. This results in the construction of an odour-quality score-sheet for subsequent use 
in a directed description mode. Each of the many qualities is then scored separately by about ten judges and the general composition of the odour quality of the materials under test may be built up. The method is illustrated by the application of it and other sensory methods to an investigation of the major odour-contributing constituents of bilberry juice (von Sydow, Andersson, Anjou, Karlsson, Land \& Griffiths, 1970).

Studies of the volatile constituents of fresh press-juice from bilberries, carried out in Sweden, showed that a particular region of the gas chromatogram was associated with the characteristic aroma of bilberries (Fig. 2). Only three substancestrans-2-hexenal, ethyl 2-methyl butyrate and ethyl 3-methyl butyrate-were detected and identified in this region. The problem was to see if a mixture of only these three substances could be made identical in aroma with fresh bilberry juice. A detailed breakdown of odour qualities was needed to provide information on which to base

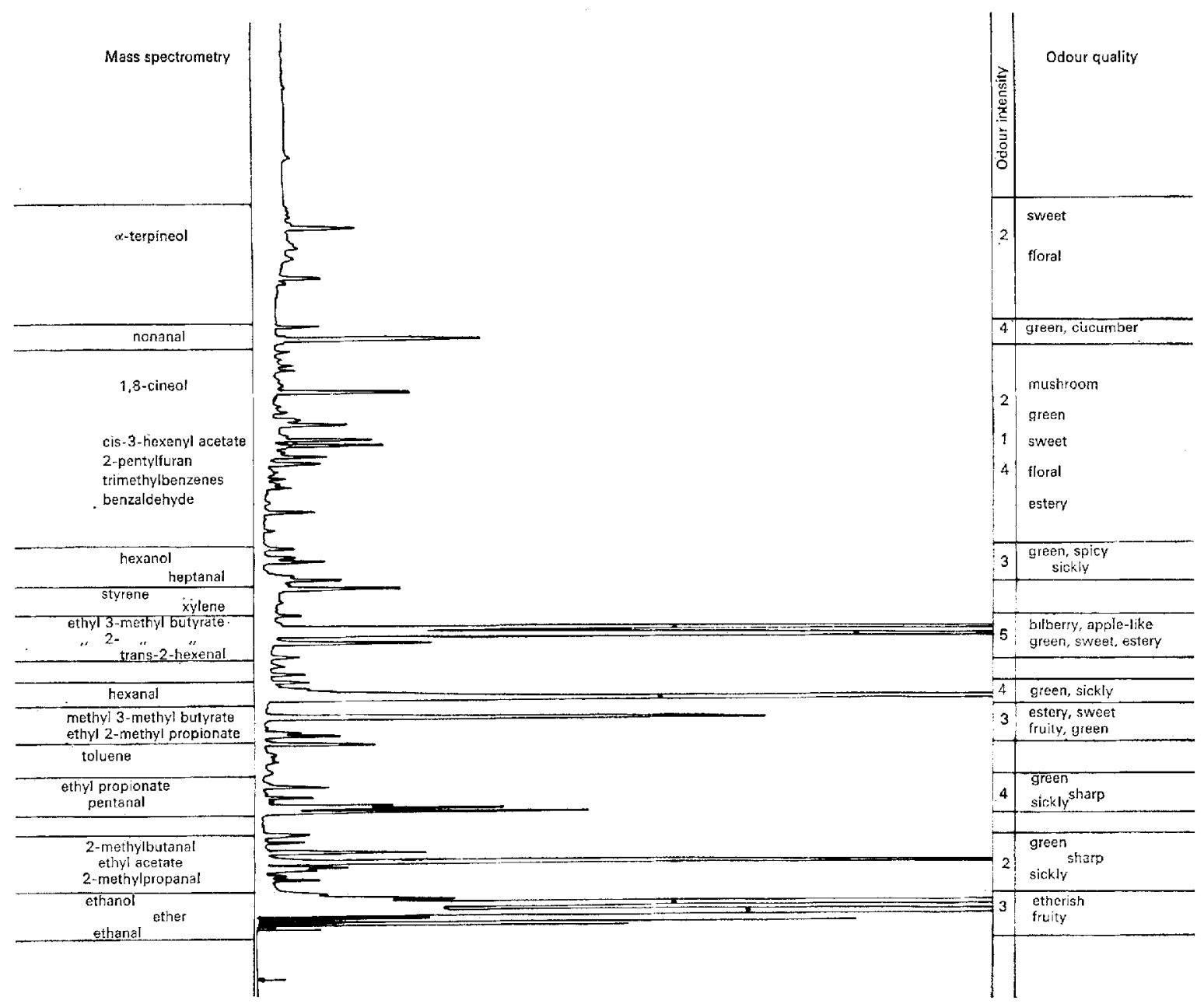

Fig. 2. Gas chromatogram of the volatile substances from fresh bilberry juice, including mass spectrometric identifications and odour assessments. 
variations in composition of mixtures. The score-sheet used (von Sydow et al. 1970) was in the form used in the prior study (Harper, Land et al. 1968). For each quality, the question 'How much if any of this quality is present?' was answered in sequence on the score-sheet.

Preliminary results showed that mixtures in aqueous solutions, of equal $\mathrm{pH}$ and solids content to that of bilberry juice, were completely different in odour from the fresh juice. All further work was carried out using deodorized (vacuum-stripped) juice as a solvent. The major qualities present in the fresh juice are shown in Table 2 together with mean panel scores and mean ranges for these qualities for all seven samples studied. The ranges are used as an indication of the scatter of the data because of the small numbers involved.

Table 2. Mean panel scores for major odour qualities of fresh bilberry juice and mean ranges for these qualities for the seven samples studied

(Ten judges)

\begin{tabular}{lcc}
\multicolumn{1}{c}{ Quality } & $\begin{array}{c}\text { Mean panel score } \\
\text { (five replications) }\end{array}$ & $\begin{array}{c}\text { Mean deviations } \\
\text { (all samples) }\end{array}$ \\
Fruity & $25 \cdot 6$ & $\pm \mathbf{2} \cdot 3$ \\
Green, cut-grass etc. & $\mathrm{I} \cdot \mathbf{4}$ & $\pm \mathbf{I} \cdot 9$ \\
Swcet & $\mathrm{I2} \cdot 6$ & $\pm \mathbf{2} \cdot 0$ \\
Apple-like, raw & $\mathrm{I} \mathbf{2} \cdot 4$ & $\pm 2 \cdot 5$ \\
Blackberry & $\mathbf{I 2} \cdot 0$ & $\pm \mathrm{I} \cdot 4$ \\
Fragrant & $8 \cdot 4$ & $\pm \mathrm{I} \cdot 5$ \\
Apple-like, cooked & $8 \cdot 2$ & $\pm \mathrm{I} \cdot 9$ \\
Total of specific fruit & & \\
qualities & $47 \cdot 0$ &
\end{tabular}

The mixtures in deodorized juice were characterized and the differences in major qualities from fresh juice are shown in Fig. 3, together with the composition of each mixture. One of the mixtures (no. 3) is clearly very similar to the fresh juice in all but two of the qualities, and another (no. 4) is also fairly close. This discrepancy is related to the increased concentration of trans-2-hexenal compared with fresh bilberry juice. Fig. 2 shows many regions of the chromatogram in which 'green' qualities are present, and the increased concentration of trans-2-hexenal compensates for these but at the same time contributes to 'raw-apple' qualities. If it had been possible to provide some 'green' quality with some other substance which did not contribute any 'raw-apple' quality, it should be possible to reduce the concentration of trans-2hexenal and, thus, the level of the 'raw-apple' quality to the level present in the fresh juice. However, as this was not possible at the time, the closeness of the match was studied using triangle and ranking methods on mixtures 3 and 4 .

In the triangle test, two control and one test sample (or vice versa) are presented under rigorously controlled conditions. The task is to indicate which sample is the odd one. The results of this test, which is very sensitive, are given in Table 3 . The results demonstrate, as expected, a highly significant difference between the fresh and deodorized juices, but that an only just significant difference was detected between the fresh juice and mixture 3 and a more significant difference between the 


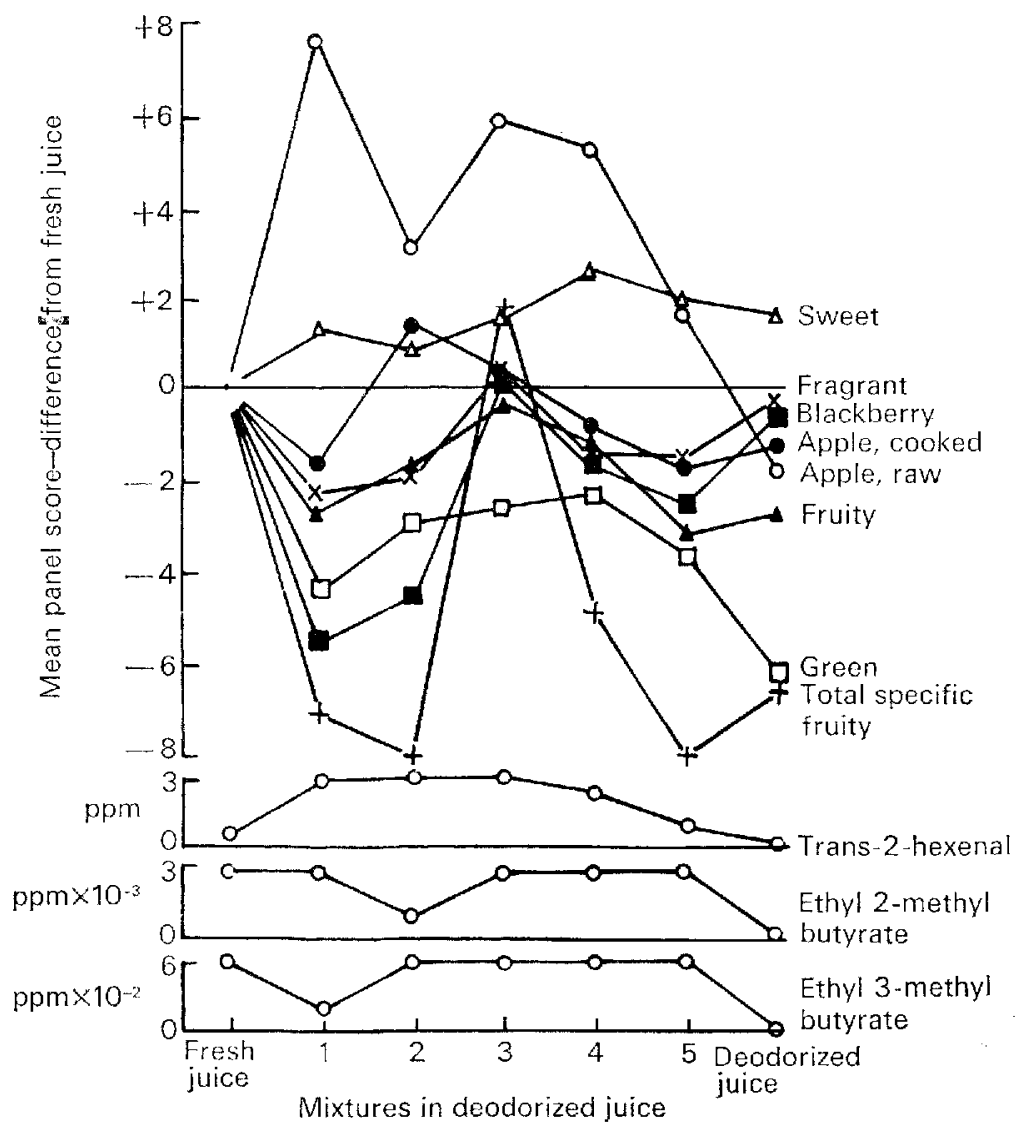

Fig. 3. Similarities in mean panel scores for the main odour qualities between fresh bilberry juice and mixtures in deodorized bilberry juice. The concentrations of the three solutes used are shown below.

fresh juice and mixture 4 . The comments of the panel on the difficulty of the task reinforces this result. A similar use of triangle tests for testing mixtures of apple juice volatiles has been described by Guadagni (I 968 ).

Table 3. Results of triangle tests on bilberry juice and mixtures in deodorized juice

\begin{tabular}{|c|c|c|c|c|}
\hline Pair & Judges & $\begin{array}{c}\text { Correct } \\
\text { decisions }\end{array}$ & $\begin{array}{c}\text { No } \\
\text { difference }\end{array}$ & $\begin{array}{c}\text { Significance } \\
\text { level }\end{array}$ \\
\hline Fresh juice & ro & 8 & I & $P<0.01$ \\
\hline Deodorized juice & II & 10 & 0 & $P=0.001$ \\
\hline Total & 21 & 18 & $\mathbf{I}$ & $P<0.001$ \\
\hline Fresh juice & $\mathbf{I} \mathbf{I}$ & 6 & I & NS \\
\hline Mixture 3 & II & 7 & $\mathbf{I}$ & $P<0.05$ \\
\hline Total & 22 & $\mathbf{r}_{3}$ & 2 & $P<0.05$ \\
\hline Fresh juice & IO & 7 & $\circ$ & $P=0.05$ \\
\hline Mixture 4 & I I & 7 & I & $P<0.05$ \\
\hline Total & 21 & 14 & $\mathbf{I}$ & $P<0.01$ \\
\hline
\end{tabular}


A further confirmation of the closeness of the match was obtained by ranking tests which are rather less sensitive than the triangle test. These consist of giving a series of samples and asking the panel to place them in order of 'bilberry-ness'. The results (Table 4 ), analysed according to Kramer ( 1963 ), show that only the deodorized juice was significantly different from the fresh juice.

Table 4. Results of ranking tests on bilberry juice and mixtures in deodorized juice

\begin{tabular}{|c|c|c|c|c|c|}
\hline \multirow[b]{2}{*}{ Expt } & \multirow[b]{2}{*}{$\begin{array}{l}\text { Number } \\
\text { of subjects }\end{array}$} & \multicolumn{4}{|c|}{ Rank totals } \\
\hline & & Juice & $\underset{3}{\text { Mixture }}$ & $\underset{4}{\text { Mixture }}$ & $\begin{array}{c}\text { Deodorized } \\
\text { juice }\end{array}$ \\
\hline 1 & I I & 22 & 25 & 26 & $37^{*}$ \\
\hline 2 & I I & 24 & $2 I \cdot 5$ & 27 & $37.5^{*}$ \\
\hline 3 & 10 & $16 *$ & 21 & 24.5 & $35^{*}$ \\
\hline 4 & 10 & 19.5 & $24 \cdot 5$ & 245 & $35^{*}$ \\
\hline
\end{tabular}

*Different from others at $5 \%$ level.

It therefore appears that much of the characteristic odour of bilberry can be accounted for by means of the three substances studied, particularly if some other 'green' contributing substance is also included. It is, however, noteworthy that as the same mixture in an aqueous base is so different from that in deodorized juice, there must be an important contribution from substances present in the deodorized juice but not so far detected by the sophisticated analytical methods used.

This illustrates one approach to characterization of the important substances in the usually very complex mixtures of volatile substances present in foods. A rather different approach has been used very elegantly on 'Delicious' apple essence by Flath, Black, Guadagni, McFadden \& Schultz, (1967). Odour units, based on the number of times by which the threshold concentration of individual constituents with odour related to the essence is exceeded, are used to indicate the relative importance of each constituent to the odour of the whole.

These examples, which had been discussed in some detail, illustrate some of the ways in which flavour can be measured and demonstrate that sensory methods, even those involving descriptive techniques which are notoriously subjective, can give useful, informative and reliable data when used with care.

Permission from Forster-Verlag A. G. to reproduce Fig. 2 and Tables 3 and 4 from Lebensmittel Wissenschaft und Technologie is gratefully acknowledged.

\section{REFERENCES}

Amerine, M. A., Panghorn, R. M. \& Roessler, E. B. (I965). Principles of Sensory Evaluation of Food. London: Academic Press.

ASTM (1968). Manual on Sensory Testing Methods, STP no. 434. Philadelphia: American Society for 'Testing and Materials.

Flath, R. A., Black, D. R., Guadagni, D. G., McFadden, W. H. \& Schultz, T. H. (1967). J. agric. Fd Chem. 15, 29 .

Guadagni, D. G. (1968). In Correlation of Subjective-Objective Methods in the Study of Odors and Taste, STP 440 p. 36. Philadelphia: American Society for Testing and Materials. 
Hall, B. A., Tarver, M.-G. \& McDonald, J. G. (1959). Fd Technol., Champaign I3, 699.

Harper, R., Bate-Smith, E. C. \& Land, D. G. (1968). Odour Description and Odour Classification. London: J. \& A. Churchill.

Harper, R., Bate-Smith, E. C., Land, D. G. \& Griffiths, N. M. (r968). Perfum. essent. Oil Rec. 59, 22.

Harper, R., Land, D. G., Griffiths, N. M. \& Bate-Smith, E. C. (1968). Br. F. Psychol. 59, 231.

Kramer, A. (1963). Fd Technol., Champaign 17, т596.

Kramer, A. \& Ditman, L. P. (I956). Fd Technol., Champaign Io, I 55.

Mahoney, C. H., Stier, D. L. \& Crosby, E. A. (1957a). Fd Technol., Champaign rx, Suppl. p. 29.

Mahoney, C. H., Stier, D. L. \& Crosby, E. A. (1957b). Fd Technol., Champaign I1, Suppl. 37.

Sjöström, L. B., Cairncross, S. E. \& Caul, J. F. (1957). Fd Technol., Champaign rx, Suppl. p. 20.

von Sydow, E., Andersson, J., Anjou, K., Karlsson, G., Land, D. G. \& Griffiths, N. M. (1970). Lebensm.-Wiss. u. Technol. 3, $\mathrm{I}$.

'Tilgner, D. J. (1962). Fd Technol., Champaign 16, no. 2, 26.

Tilgner, D. J. (1965), Fd Technol., Champaign 19, 25.

Tukey, J. W. (1953). Trans. N.Y. Acad. Sci. Ser II r6, (2) 88.

\title{
On making food attractive
}

\author{
By Roland Harper, Department of Food Science, University of Reading
}

Nutritional programs must recognize the importance of attractiveness of foods. The attractiveness of foods-their flavor, texture, odor and appearance-is nutritionally important since foods are nutritious only when consumed. Consumer acceptance is thus vital to their nutritional value,' (Anonymous, 1969.)

\section{Some historical aspects}

By tradition, much relevant information on making food attractive is contained in books on household management and cookery. We immediately think of Mrs Beeton, but it is possible to find important contributions much earlier. Going no further back than the eighteenth century, The Lady's Companion (Anonymous, I753) with its detailed 'instructions for marketting' and The Art of Cookery Made Plain and Easy (Gasse, 1784) provide two examples. The importance of attractive food is also made explicit in an article on dietetics in the literary edition of Encyclopaedia Britannica (Anonymous, 1878 ) as indicated thus:

'The application of science to the relation of the continuous demands of the body for nutriment aims mainly at three objects, Health, Pleasure and Economy.'

And later: 'A man need not consider that he is wasteful when he spends money upon making his bill of fare palatable and provocative of indulgence even to the extent of moderate superfluity. Pleasure and prudence walk hand in hand.'

Over the years many innovators, both domestic and commercial, could be named. The importance of making food attractive was largely ignored in the initial application of modern knowledge of nutrition and food science. There were many reasons for this, including perhaps an attitude of mind which considered it appropriate to give people what it was considered would do them good rather than what appealed to them. There was a general lack of appreciation among scientific investigators 